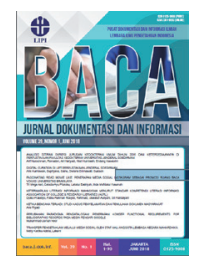

\title{
Kekuatan infografik dan perannya dalam buku pangan fungsional
}

\author{
Dhevi Enlivena Irene Restia Mahelingga ${ }^{1^{*}}$ \\ ${ }^{1}$ Balai Media dan Reproduksi LIPI \\ *Korespondensi: dhevlingga@gmail.com
}

Diajukan: 08-03-2021; Direview: 18-02-2021; Diterima: 21-04-2021; Direvisi: 25-06-2021

\begin{abstract}
Infographic potential in bridging complex data, such as research results, has the opportunity to be used to better educate and further to empower the community, especially for issues that still have not received much attention in the community, such as functional food issues. The lack of attention is due to limited access and way to deliver functional food research results so that it is difficult to be accessed and understood by the community. This is because most of the delivery of research results is still in the form of reports, journals, or books that are less interesting, both in terms of language and appearance. In terms of appearance, infographics can be used to support the effectiveness of information delivery and the process of better understanding of the community. This study discusses infographic strength and its role in functional food books compared to simple graphical data visualization using the power of visual infographic theory in attracting attention, understanding, and sticking memories into the reader's mind. The results of the study are in the form of infographic potential in accelerating information education and opening up opportunities for effectiveness in decreasing human attention span.
\end{abstract}

\begin{abstract}
ABSTRAK
Potensi infografik dalam menjembatani data yang rumit, seperti hasil penelitian, berpeluang digunakan dalam mengedukasi dan lebih jauh dapat memberdayakan, terutama untuk isu-isu yang masih belum banyak mendapatkan perhatian di masyarakat, seperti isu pangan fungsional. Kurangnya perhatian tersebut karena keterbatasan akses dan cara penyampaian hasil riset pangan fungsional sehingga sulit diakses dan dipahami oleh masyarakat. Hal ini karena sebagian besar penyampaian hasil riset masih dalam bentuk laporan, jurnal, atau buku yang kurang menarik, baik dari segi kebahasaan maupun tampilan. Dari sisi tampilan, infografik bisa digunakan dalam mendukung efektivitas penyampaian informasi dan proses pemahaman yang lebih baik kepada masyarakat. Kajian ini membahas kekuatan infografik dan perannya dalam buku pangan fungsional dibandingkan dengan visualisasi data grafik sederhana menggunakan teori kekuatan visual infografik dalam menarik atensi, memahamkan, dan menancapkan ingatan ke benak pembaca. Hasil kajian berupa potensi infografik dalam mempercepat edukasi informasi dan membuka peluang efektivitas terhadap rentang perhatian manusia yang semakin menurun.
\end{abstract}

Keywords: Infographic; Data visualization; Book content; Information analytics; Functional food

\section{PENDAHULUAN}

Manusia adalah makhluk visual yang memproses gambar lebih banyak daripada teks atau suara. Sejak ribuan tahun yang lalu, penghuni gua menggunakan gambar visual untuk mencatat waktu, menggambarkan hewan buruan, dan merekam perayaan. Perkembangan peradaban menciptakan hieroglif dan simbol visual untuk huruf dan angka, menyediakan kode untuk mengatur komunikasi manusia (Beegel, 2014). Sampai saat ini manusia tidak bisa lepas dari komunikasi visual. Komunikasi visual mengepung manusia dengan berbagai bentuk: logo, sign system, ikon, simbol, peta, dan grafik. Melalui bentuk-bentuk tersebut, pemahaman terkait informasi di dalamnya menjadi lebih cepat tersampaikan. 
Berkat kekuatan ikon sederhana, wisatawan yang berkunjung ke benua manapun dapat dengan mudah menemukan rumah sakit, rumah makan, dan toilet yang benar. Hal ini membuktikan bahwa komunikasi visual dapat menjembatani perbedaan budaya. Penggunaan komunikasi visual menjadi semakin kompleks, tidak hanya untuk merepresentasikan hal yang sederhana dan umum tetapi juga hal yang rumit dan khusus. Pada level tersebut bentuk komunikasi visual yang efektif digunakan adalah berupa infografik.

Potensi infografik dalam menjembatani data yang rumit, seperti hasil penelitian agar lebih mudah dipahami oleh masyarakat, berpeluang digunakan dalam mengedukasi dan lebih jauh dapat memberdayakan. Terutama untuk isu-isu yang masih belum banyak mendapatkan perhatian di masyarakat, seperti isu pangan fungsional di Indonesia. Isu pangan fungsional perlu mendapat perhatian, sejalan dengan meningkatnya angka harapan hidup yang berdampak pada pemeliharaan kesehatan yang semakin naik dalam rangka mencegah risiko penyakit. Aspek preventif ini menjadikan pangan fungsional sebagai alternatif dalam mencegah risiko penyakit sekaligus pemeliharaan kesehatan. Pangan fungsional menjadi strategi untuk segera mendapat dukungan dari seluruh elemen masyarakat, baik regulator, akademisi/litbang, industri, dan masyarakat.

Berdasarkan Laporan Kemajuan "Penerapan Skema Inkubasi Publikasi untuk Meningkatkan Produktivitas Buku Ilmiah di Bidang Pangan Fungsional”, telah banyak artikel jurnal dan prosiding yang dihasilkan oleh individu peneliti LIPI di bidang pangan fungsional. Akses publik dan pemangku kepentingan terkait dengan publikasi berupa buku hasil-hasil penelitian pangan fungsional masih sangat minim (Helmi, 2018). Padahal LIPI telah memiliki satuan kerja bidang penerbitan ilmiah yakni LIPI Press yang telah mapan dan menjadi tujuan studi banding penerbitan ilmiah lembaga/kementerian lain di Indonesia, sekaligus juga telah menjalin kerja sama dengan perusahaan penerbitan global Springer dalam penerbitan internasional beberapa buku terbitan LIPI Press (Mahelingga, 2020).

Merujuk data publikasi buku hasil-hasil penelitian LIPI yang diterbitkan oleh LIPI Press yang telah sampai ke publik melalui jalur distribusi komersial, dari total buku yang sampai kepada masyarakat, baru $22,21 \%$ publikasi buku di bidang ilmu hayati dan hanya $0,82 \%$ buku yang spesifik mengulas pangan fungsional (Helmi, 2018). Berdasarkan data tersebut, dapat dipahami bahwa hasil penelitian bidang pangan fungsional kurang dapat dimanfaatkan oleh masyarakat. Penyimpulan tersebut karena laporan penelitian, jurnal, dan prosiding masih berada di tataran kebahasaan dan penyajian yang berbeda dengan buku yang lebih umum, dari segi aksesibilitas masyarakat tidak semudah buku.

Penyajian informasi dalam bentuk buku memungkinkan hasil penelitian dapat disampaikan dengan lebih leluasa. Data dan tabel dapat diolah dengan sedemikian rupa menggunakan visualisasi dan infografik yang lebih bebas dibandingkan laporan penelitian konvensional. Meski demikian, tidak jarang pula terdapat buku yang masih menggunakan data, tabel, dan grafik sederhana yang masih asli dari hasil penelitian. Berdasarkan hal tersebut, timbul pertanyaan terkait bentuk visualisasi data dan infografik seperti apa yang digunakan dalam buku pangan fungsional dan bagaimana visualisasi data dan infografik tersebut dapat menyampaikan informasi. Pertanyaan kajian ini yaitu bagaimana visualisasi data dan infografik diterapkan dalam buku bidang pangan fungsional. Selain itu juga membandingkan keduanya sehingga didapatkan bagaimana kekuatan infografik sebagai penyampai informasi yang lebih baik.

\section{TINJAUAN PUSTAKA}

Infografik tampak sebagai bentuk komunikasi modern, tetapi akar dari infografik sudah ada sejak abad ke-18. Pada 1786, William Playfair menerbitkan The Commercial and Political Atlas, yang menggunakan grafik untuk mengilustrasikan fakta-fakta tentang keadaan ekonomi Inggris saat itu. Playfair secara umum diterima sebagai penemu grafik garis, diagram batang, dan diagram lingkaran (Beegel, 2014). 
Infografik untuk penggunaan editorial dipopulerkan pada akhir 1930-an dan awal 1940-an, dengan Majalah Fortune menjadi salah satu penyaji awal infografik yang paling terkenal. Infografik pada majalah tersebut dikerjakan dengan keterampilan yang baik, dicirikan tidak hanya menggunakan gaya yang ikonik, tetapi perhatian yang teliti terhadap detail (Lankow, Ritchie, \& Crooks 2012). Infografik dari Majalah Fortune yang terbit pada Juli 1946 dapat dilihat pada Gambar 1.

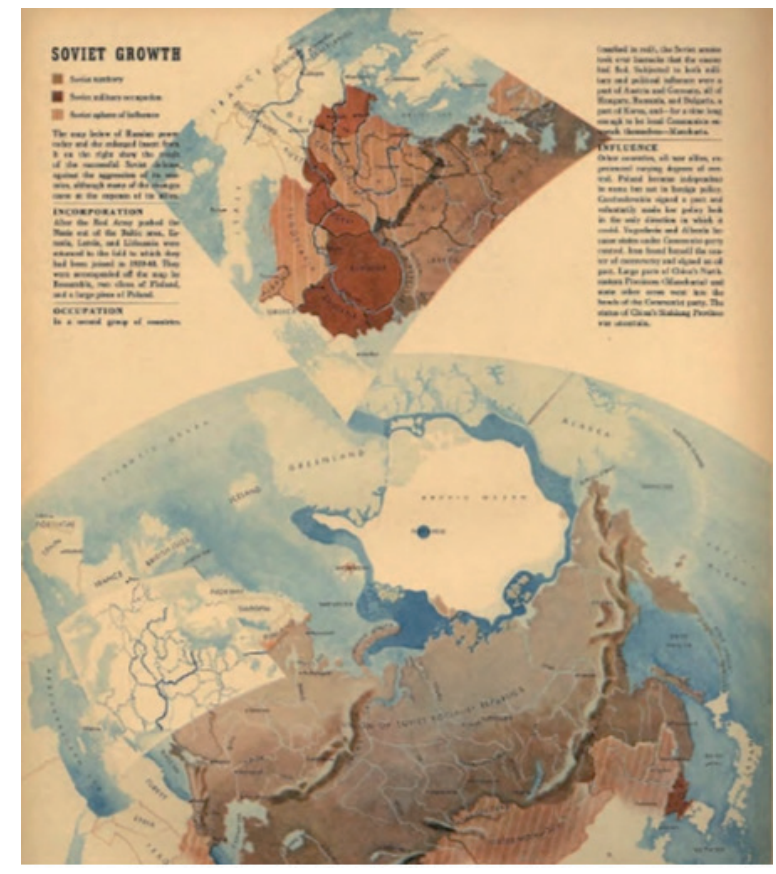

Gambar 1. Infografik Soviet Growth di majalah Fortune edisi Juli 1946 (Lankow, Ritchie, \& Crooks, 2012)

Pada 1970-an, infografik semakin populer dan beragam penggunaannya di surat kabar serta majalah, berupa bagan, peta, dan diagram untuk mengilustrasikan dan mempertajam berita serta pemisah kolom teks (Beegel, 2014). Infografik semakin berkembang terutama setelah masuknya era desain digital yang semakin memudahkan pembuatan infografik yang lebih atraktif. Infografik tidak hanya ada di media cetak, melainkan juga di media elektronik, digunakan di televisi untuk laporan cuaca, berita, hingga penggunaannya di dunia maya.

\subsection{Visualisasi Data dan Infografik}

Infografik dan visualisasi data dianggap sama, tetapi di dunia perancang infografik modern, keduanya memiliki arti yang berbeda. Visualisasi data adalah representasi visual dari nilai-nilai numerik. Bagan dan grafik adalah visualisasi data dan membuat gambar dari kumpulan data tertentu. Hal tersebut adalah cara yang efisien untuk mengomunikasikan data. Visualisasi data dapat sangat menghemat ruang dengan memvisualisasikan sejumlah besar angka dalam ruang yang kecil. Dengan merancang visualisasi yang menampilkan semua data dalam sudut pandang pembaca, memungkinkan kita untuk melihat seluruh kumpulan data dengan gerakan mata minimal tanpa menggulir atau membalik-balik halaman (Krum, 2013).

Sementara itu, penggunaan istilah infografik menyiratkan lebih dari sekadar visualisasi data. Istilah infografik telah berkembang menuju definisi baru yang berarti desain grafis yang lebih besar yang menggabungkan visualisasi data, ilustrasi, teks, dan gambar bersama-sama ke dalam format yang menceritakan kisah secara lengkap. Visualisasi data sendiri tidak lagi dianggap sebagai infografik tetapi merupakan alat yang ampuh yang sering digunakan perancang untuk membantu menceritakan kisah mereka secara visual dalam infografik (Krum, 2013). 
Desain infografik memungkinkan untuk menceritakan kisah dan berbagi informasi atau data dengan cara yang merangsang secara visual, di mana konten dipahami dengan lebih mudah dan lebih akurat. Saat mendesain infografik, ada aturan tertentu yang harus diikuti. Dalam hal bahasa visual, gaya gambar, font yang digunakan, penyajian informasi yang diringkas, pengaturan warna, dan navigasi ikonografi. Semua harus diatur sedemikian rupa untuk mengekspresikan konten, alih-alih mengutamakan estetika yang mengesampingkan informasi (SendPoints, 2015).

\subsection{Kekuatan Infografik}

Kekuatan infografik dalam mengedukasi merupakan potensi yang terus digali sesuai dengan data atau informasi yang ingin disampaikan. Terkait jenis informasi yang ingin disampaikan atau tujuannya, (Beegel, 2014) membagi infografik menjadi tiga kelompok, yaitu:

1. Menunjukkan bagaimana melakukan sesuatu atau bagaimana sesuatu bekerja. Visual infografik digunakan untuk mendemonstrasikan langkah-langkah dari suatu proses. Grafik-grafik dan gambar digunakan untuk membantu pembaca memahami proses atau langkah-langkah yang rumit. Setiap instruksi manual adalah infografik.

2. Mengilustrasikan sebuah poin. Informasi dan data statistik merupakan fondasi dari infografik dalam kategori ini.

3. Memotivasi seseorang untuk bertindak. Infografik jenis ini ditujukan untuk mendorong pembaca atau pemirsa untuk melakukan sesuatu

Dalam penerapannya, ketiga kelompok infografik tersebut dapat digunakan secara bersamaan atau saling melengkapi sesuai kebutuhan konteks yang ingin disampaikan. Lankow, Ritchie, \& Crooks (2012) menjelaskan ada tiga kekuatan utama infografik begitu powerful sebagai penyampai informasi dan edukasi, yaitu:

1. Daya Tarik. Infografik secara visual merangsang dan menarik. Visual infografik mampu menarik perhatian sebelum informasi disintesis.

2. Pemahaman. Otak manusia telah diatur secara otomatis menginterpretasikan isyarat visual, memungkinkan pemahaman hampir seketika dengan hanya sedikit usaha.

3. Ingatan. Visualisasi memicu kita untuk menarik informasi menjadi ingatan jangka panjang. Visualisasi memungkinkan pembaca untuk mengakses informasi yang sebenarnya sudah tersimpan di otak, yang kemudian dapat memperkuat konsepnya.

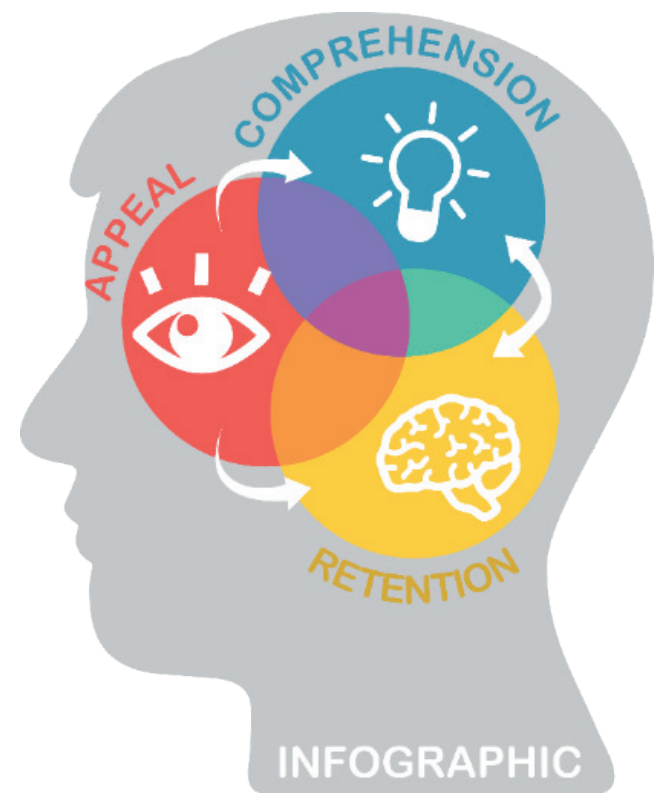

Gambar 2. Bagaimana kita menyukai infografik 


\subsection{Potensi Infografik}

Kekuatan infografik dalam percepatan edukasi telah terbukti sejak Zaman Victoria (1837-1901), dibuktikan oleh infografik yang dibuat oleh Florence Nightingale untuk menunjukkan penyebab kematian Tentara Inggris selama Perang Krimea (1853-1856). Infografik Florence Nightingale berjudul Diagram of the Causes of Mortality in the Army in the East (Gambar 3) disampaikan kepada parlemen yang sebelumnya tidak responsif terhadap masalah kesehatan dan kebersihan pasukan. Melalui infografik tersebut, Florence Nightingale memberikan terobosan dalam membawa cara berpikir baru tentang penyebaran penyakit (Lankow, Ritchie, \& Crooks 2012). Catatan sejarah Florence Nightingale dalam menyampaikan data berupa infografik yang mampu menggerakkan orang yang membaca dan pada akhirnya mengubah pola pikir secara masif, membuktikan bahwa infografik merupakan cara penyampaian informasi yang efektif.

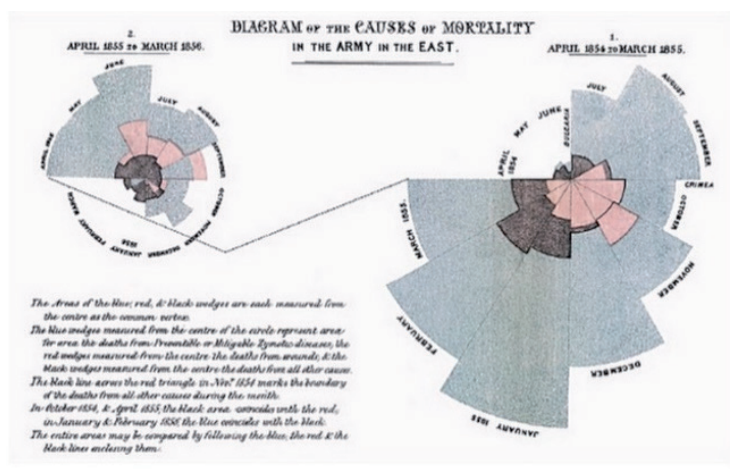

Gambar 3. Diagram of the Causes of Mortality in the Army in the East (Lankow, Ritchie, \& Crooks, 2012)

\subsection{Rentang Waktu Perhatian}

Rentang waktu perhatian manusia mengalami penurunan (Microsoft, 2015) sejalan dengan laporan penelitian Microsoft Kanada yang diterbitkan dalam bentuk Consumer Insight pada tahun 2015 tentang rentang waktu perhatian (attention spands). Pada tahun 2000, rata-rata rentang perhatian manusia berada di angka 12 detik. Sementara itu, pada 2013 rentang perhatian manusia menurun menjadi 8 detik. Capaian tersebut bahkan lebih rendah dibandingkan rata-rata rentang perhatian ikan mas koki, sebagaimana yang terlihat pada Gambar 4.

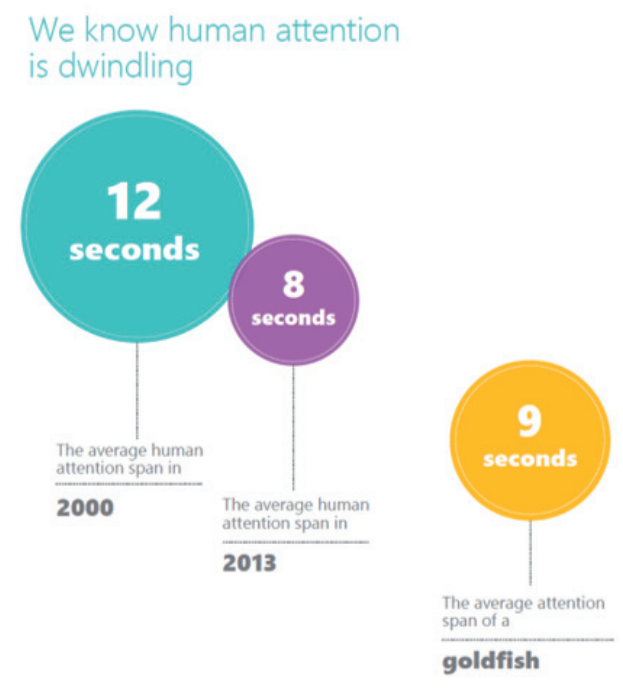

Gambar 4. Penurunan rentang perhatian manusia (Microsoft, 2015) 
Rentang perhatian adalah jumlah waktu yang dapat difokuskan oleh seorang individu pada satu orang, objek, atau aktivitas (Fiorentino, 2004). Selanjutnya, perhatian individu akan terdistraksi dan perlu terus memperbaharui konsentrasinya agar tetap fokus pada satu hal. Begitu minimnya waktu manusia untuk dapat berkonsentrasi atau fokus pada satu hal, membuat banyak penyedia informasi seperti pengelola artikel website dan redaksi koran atau majalah, mengkaji ulang strategi penyampaiannya. Dalam dunia jurnalisme dikenal sebutan story hook atau opening yakni kalimat di awal artikel yang dibuat menarik, cenderung bombastis, untuk memikat perhatian pembaca. Hal tersebut diupayakan agar dapat memikat perhatian manusia yang sedemikian mudah teralihkan. Salah satu strategi lainnya bagi pembuat konten adalah menyampaikan informasi dengan merangkum dan mengemas informasi tersebut menjadi sebuah infografik.

\subsection{Pangan Fungsional}

Dalam buku Functional Food: from Sciences to Health and Claims, dinyatakan definisi pangan fungsional adalah bahan makanan yang bermanfaat memengaruhi satu atau lebih fungsi di dalam tubuh, memiliki nilai tambah kandungan nutrisi, meningkatkan kesehatan, dan/atau mengurangi risiko penyakit. Pangan fungsional bukan pil atau suplemen, tetapi makanan yang dikonsumsi seperti layaknya makanan normal. Pangan fungsional bisa dihasilkan melalui penambahan komponen atau memodifikasi komponen makanan tersebut dengan cara enzimatik, kimiawi, bioteknologi, atau modifikasi lainnya untuk memberikan lebih banyak manfaat (Howlett, 2008).

Di Indonesia telah diperkenalkan pangan fungsional melalui berbagai macam produk yang terus dikembangkan. Keseriusan pemerintah di bidang pangan fungsional tertuang dalam Perka BPOM RI No. HK 00.05.52.0685 Tahun 2005 tentang Ketentuan Pokok Pengawasan Pangan Fungsional. Dalam Perka BPOM ini didefinisikan mengenai pangan fungsional, yakni pangan olahan yang mengandung satu atau lebih komponen fungsional yang berdasarkan kajian ilmiah mempunyai fungsi fisiologis tertentu, terbukti tidak membahayakan, dan bermanfaat bagi Kesehatan (BPOM RI, 2005). Sementara itu, klaim manfaat fungsional diperbaharui melalui Perka BPOM RI No. 13 Tahun 2016 tentang Pengawasan Klaim pada Label dan Iklan Pangan Olahan (BPOM RI, 2016).

Kekayaan pangan tradisional Indonesia sangat beragam dan diyakini mempunyai khasiat tertentu bagi Kesehatan (Hariyadi, 2006). Berbagai kekayaan lokal yang penting dan berharga tersebut perlu disadari, digali, dan dikembangkan oleh lembaga R\&D baik swasta maupun pemerintah (Hariyadi, 2015). Sebagai lembaga riset pemerintah, Lembaga Ilmu Pengetahuan Indonesia (LIPI) berkomitmen dalam mewujudkan kehidupan yang lebih baik, ditunjukkan dengan memberi solusi pada persoalan ketahanan pangan, kesehatan, dan lingkungan yang lebih sehat (Pudjiastuti, 2017). Salah satu kontribusi LIPI di bidang pangan adalah melalui penelitian pangan fungsional.

\section{METODE}

Jenis penelitian ini yaitu deskriptif-kualitatif. Penelitian ini mengambil sudut pandang site of production dalam memperlakukan objek visual yang sedang diamati. Site of production atau wilayah produksi (visual) lebih cenderung untuk mengurai area produksi atau pembuatan gambar visual (Ida, 2014). Pendekatan yang digunakan adalah pendekatan objek visual melalui bentuk/format dan style objek visual. Pendekatan tersebut dapat menggali lebih jauh tentang karakteristik bentuk/format dan style dalam desain visual dari objek yang dikaji. Penelitian ini lebih dikenal dengan penelitian 'stylistic' karena lebih fokus pada grafis dan karakteristik style objek visual seperti: warna, garis, bentuk (shape), tekstur (texture), dan tata letak (lay out) serta komposisinya. Penelitian ini lebih fokus pada aspek-aspek instrinsik desain grafis visual objek yang diteliti. Asumsi yang dipakai oleh tradisi ini adalah untuk memahami budaya visual dengan meletakkan pada posisi struktur dari spektrum bentuk/format dan stylistic-nya (Ida, 2014).

Batasan objek penelitian adalah buku terbitan LIPI Press yang berkaitan dengan bidang pangan fungsional, yakni Peluang Adopsi Inovasi Berbasis Data Paten di Bidang Pangan Fungsional dan 
buku Produk Pangan Berbasis Tempe dan Aplikasinya (Gambar 5). Pemilihan kedua buku tersebut didasarkan pada latar belakang penyusunan kedua buku yang berupa hasil penelitian bidang pangan fungsional dari peneliti LIPI namun berbeda dalam penyajian datanya. Untuk buku "Peluang Adopsi Inovasi Berbasis Data Paten di Bidang Pangan Fungsional" masih menggunakan penyajian data yang lebih konvensional, yakni menggunakan visualisasi data berupa grafik dan diagram sederhana. Sementara itu, buku "Produk Pangan Berbasis Tempe dan Aplikasinya" diterbitkan dengan bentuk lebih eksklusif dan penggunaan infografik untuk menyajikan data hasil penelitian.

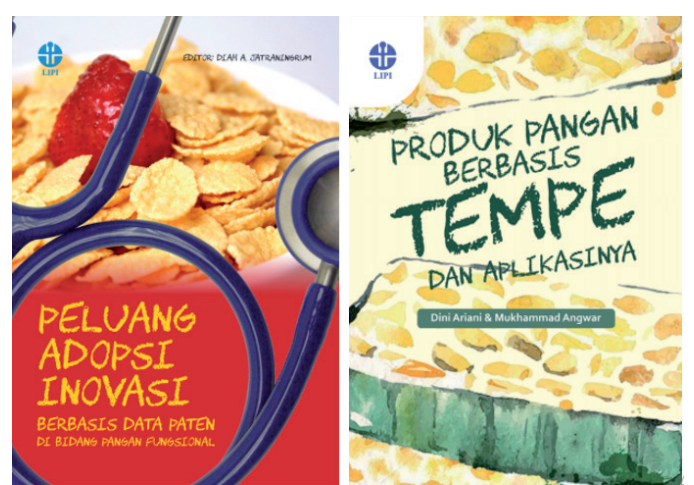

Gambar 5. Sampul buku objek penelitian (Jatraningrum et al. 2015; Ariani \& Angwar, 2018)

\section{HASIL DAN PEMBAHASAN}

\subsection{Visualisasi Data dalam Buku "Peluang Adopsi Inovasi Berbasis Data Paten di Bidang Pangan Fungsional"}

Peluang Adopsi Inovasi Berbasis Data Paten di Bidang Pangan Fungsional adalah buku berjenis bunga rampai dari Pusat Inovasi LIPI yang diterbitkan oleh LIPI Press pada 2015. Secara garis besar, tujuan penulisan buku Peluang Adopsi lnovasi Berbasis Data Paten di Bidang Pangan Fungsional adalah untuk menggugah kesadaran para pemangku kepentingan, terutama di lembaga riset, tentang pentingnya data paten untuk menganalisis posisi strategis hasil penelitian terkait dengan pangan fungsional, yang pada akhirnya dapat meningkatkan peluang pengembangan teknologi dan adopsi inovasi di bidang ini (Jatraningrum et al., 2015).

Dari segi tampilan, Peluang Adopsi Inovasi Berbasis Data Paten di Bidang Pangan Fungsional menggunakan jenis layout justified standar satu kolom dalam halaman berukuran A5. Penggunaan warna buku dominan hitam putih dan beberapa visualisasi data berupa diagram dan grafik dicetak berwarna, seperti terlihat pada Gambar 6.

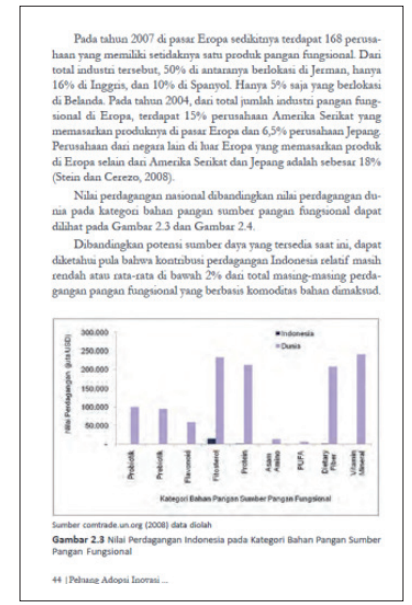

Gambar 6. Tampilan layout dalam buku Peluang Adopsi Inovasi Berbasis Data Paten di Bidang Pangan Fungsional (Helmi, 2015) 
Seluruh grafik dan diagram yang digunakan dalam naskah adalah untuk menggambarkan data hasil penelitian. Hal tersebut terlihat pada beberapa grafik dan diagram, seperti "Komposisi Bahan Pangan Fungsional Berbasis Data Paten" (hlm. 75); "Perbandingan Tingkat Keunggulan dengan Penggunaan di Kawasan Asia Pasifik dan Eropa" (hlm. 91); dan "Jumlah Portofolio Riset LIPI Fungsional LIPI Berdasarkan Kategori Bahan Pangan Fungsional” (hlm. 145). Ketiga gambar tersebut berturut-turut dapat dilihat pada Gambar 7.
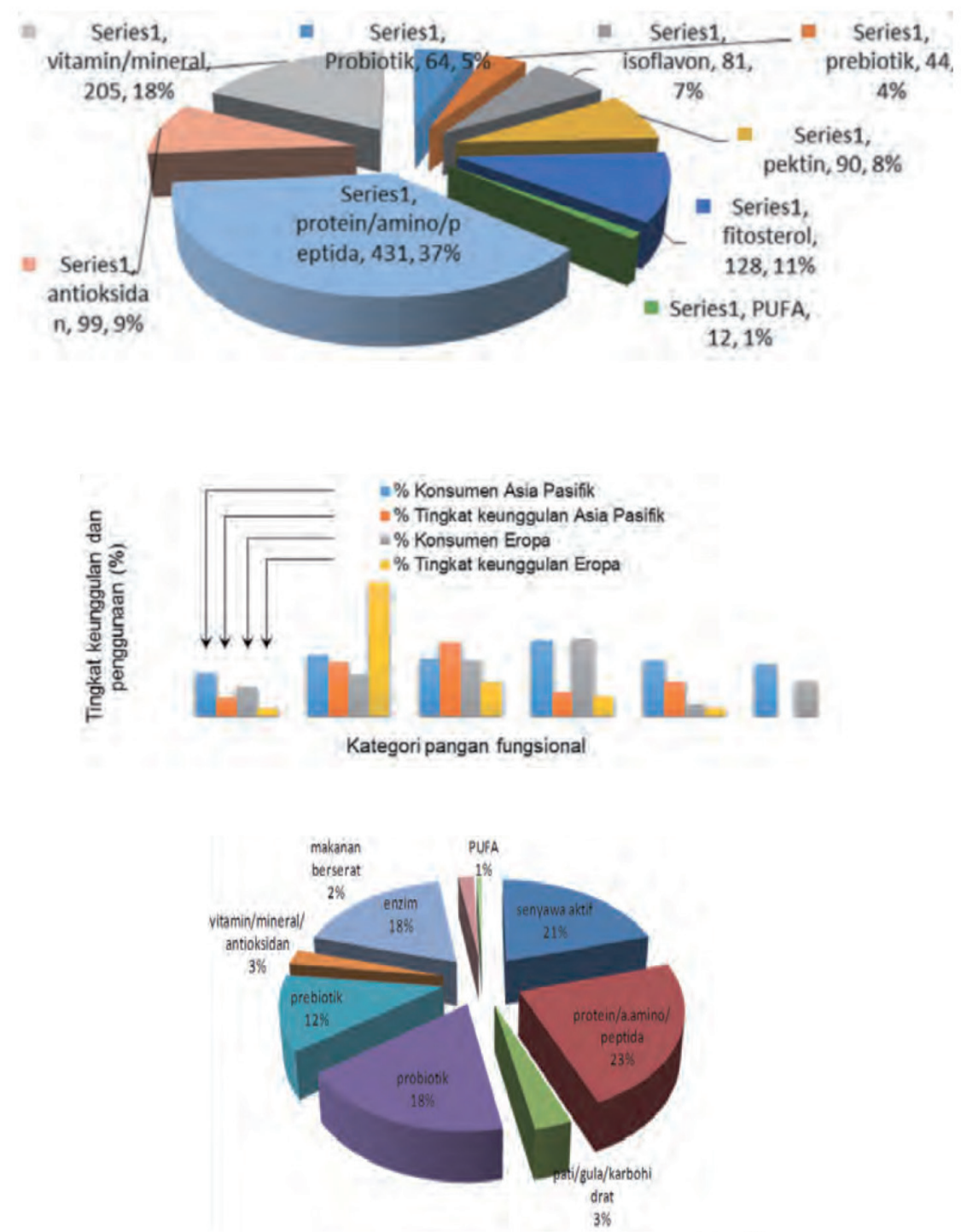

Gambar 7. Tampilan grafik dan diagram dalam buku Peluang Adopsi Inovasi Berbasis Data Paten di Bidang Pangan Fungsional (Jatraningrum \& Sachmid, 2015; Jatraningrum \& Astuti, 2015)

Gambar 7 memberikan perbedaan yang cukup jelas terkait perbandingan masing-masing datum dalam data yang ingin disampaikan. Perbedaan tersebut terlihat dari penggunaan warna yang berbeda untuk mewakili masing-masing datum. Grafik seharusnya dapat dibuat lebih familier agar dapat mengarahkan pembaca pada pemahaman dan kritik yang lebih baik (Lankow, Ritchie, \& Crooks, 2012). Grafik dan diagram dalam buku Peluang Adopsi Inovasi hanya menggunakan bentuk yang umum dengan teks standar sebagai keterangan. Penempatan dan warna teks juga tidak terlihat sempurna karena menumpuk dan menggunakan warna kurang kontras sehingga cenderung menyatu 
dengan gambar. Secara keseluruhan kekuatan hanya terletak dari penggunaan warna yang kontras dengan isi naskah yang hitam putih.

Standar grafik dan diagram seperti ini merupakan pelengkap dari teks, yang umumnya tidak terlalu memberikan informasi yang jelas. Satu-satunya yang didapatkan oleh pembaca adalah perbandingan antardatum apabila divisualisasikan dalam diagram pai atau grafik balok. Representasi dari topik yang diangkat, nama datum, dan data yang ditampilkan kurang dapat tersampaikan dengan baik, pembaca harus melihat lagi ke dalam teks naskah untuk memahami secara lebih komprehensif.

\subsection{Infografik dalam Buku Produk Pangan Berbasis Tempe dan Aplikasinya}

Buku "Produk Pangan Berbasis Tempe dan Aplikasinya" sedikit berbeda dengan buku bunga rampai Peluang Adopsi lnovasi Berbasis Data Paten di Bidang Pangan Fungsional. Buku Produk Pangan Berbasis Tempe dan Aplikasinya merupakan buku yang diterbitkan LIPI Press dalam rangka mendukung perluasan diseminasi dan mengedukasi masyarakat terkait isu pangan fungsional melalui program Insinas tahun 2018. LIPI Press menginisiasi penerbitan buku ilmiah bidang pangan fungsional tersebut secara lebih eksklusif, baik dari sisi perlakuan penerbitan maupun bentuk tampilan buku. Tampilan layout buku "Produk Pangan Berbasis Tempe dan Aplikasinya" (Gambar 8).

Secara fisik buku "Produk Pangan Berbasis Tempe dan Aplikasinya" menggunakan jenis layout justified standar satu kolom dalam halaman berukuran A5. Penggunaan warna buku full color terutama pada halaman bridging yang menggunakan ilustrasi atau gambar yang telah diolah secara artistik. Data dalam buku "Produk Pangan Berbasis Tempe dan Aplikasinya" ditampilkan dalam bentuk infografik. Dua di antaranya adalah infografik "Perkembangan Berat Badan Balita" pada Gambar 9 dan infografik "Rata-rata Berat Badan Balita" pada Gambar 10.
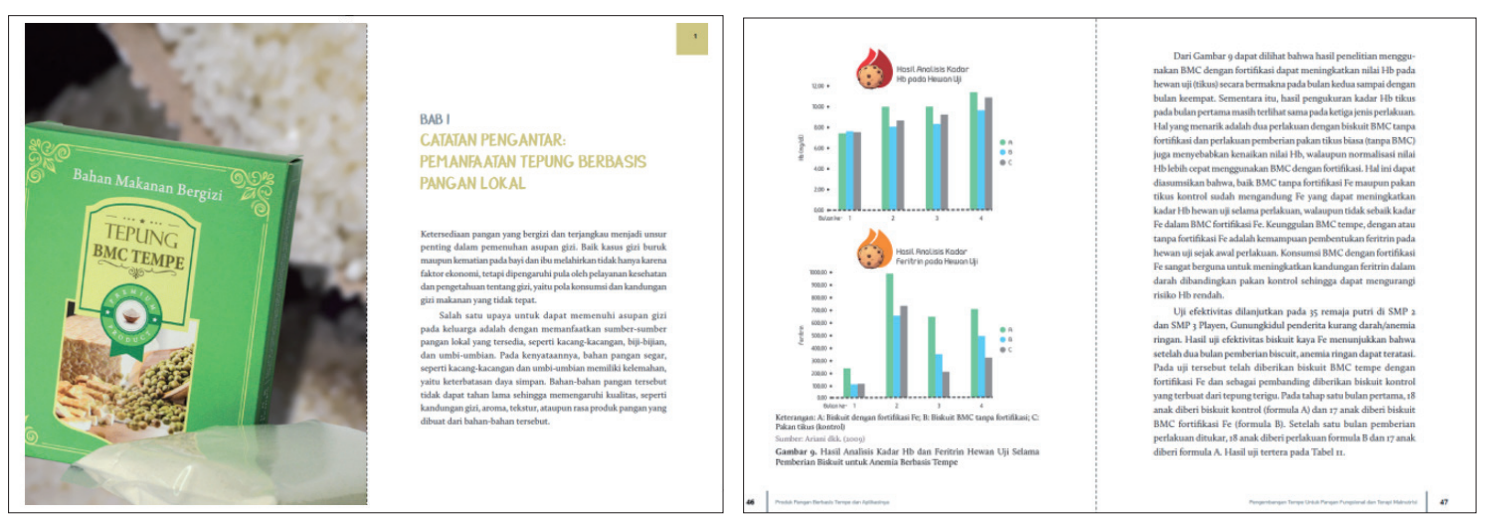

Gambar 8. Tampilan layout dalam buku Produk Pangan Berbasis Tempe dan Aplikasinya (Ariani \& Angwar, 2018)

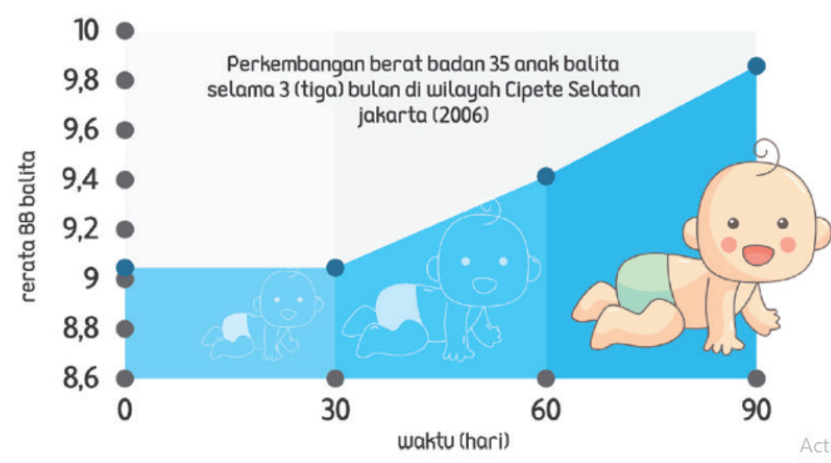

Gambar 9. Infografik "Perkembangan Berat Badan Balita" dalam buku Produk Pangan Berbasis Tempe dan Aplikasinya (Ariani \& Angwar, 2018) 
Gambar 9 merupakan infografik yang memvisualisasikan perkembangan berat badan 35 anak balita selama tiga bulan di wilayah Cipete Selatan, Jakarta tahun 2006. Dari tampilan visual yang dipilih oleh desainer. Menurut teori Lankow, kekuatan yang ditonjolkan ada pada daya tarik ilustrasi balita yang tengah merangkak. Ilustrasi tersebut menjadi semacam hook yang memperkuat infografik untuk dapat memikat atensi dalam beberapa detik pertama karena aspek visualnya yang kuat dan kemudian secara persuasif menarik pembaca untuk fokus membaca lebih jauh dan mencerna seluruh pesan (Beegel, 2014).

Pemahaman dibentuk melalui penggunaan warna dominan biru yang berbeda opacity dan semakin tajam ditambah dengan ilustrasi outline balita yang juga membesar. Memberi kesan meningkat atau membesar yang secara harafiah sesuai dengan data yang ingin disampaikan. Penyematan teks di bagian atas juga menggunakan font rounded yang memberi nuansa lembut yang senada dengan ilustrasi. Secara keseluruhan, infografik menggunakan harmoni gambar grafik, teks, dan ilustrasi untuk menjelaskan data.

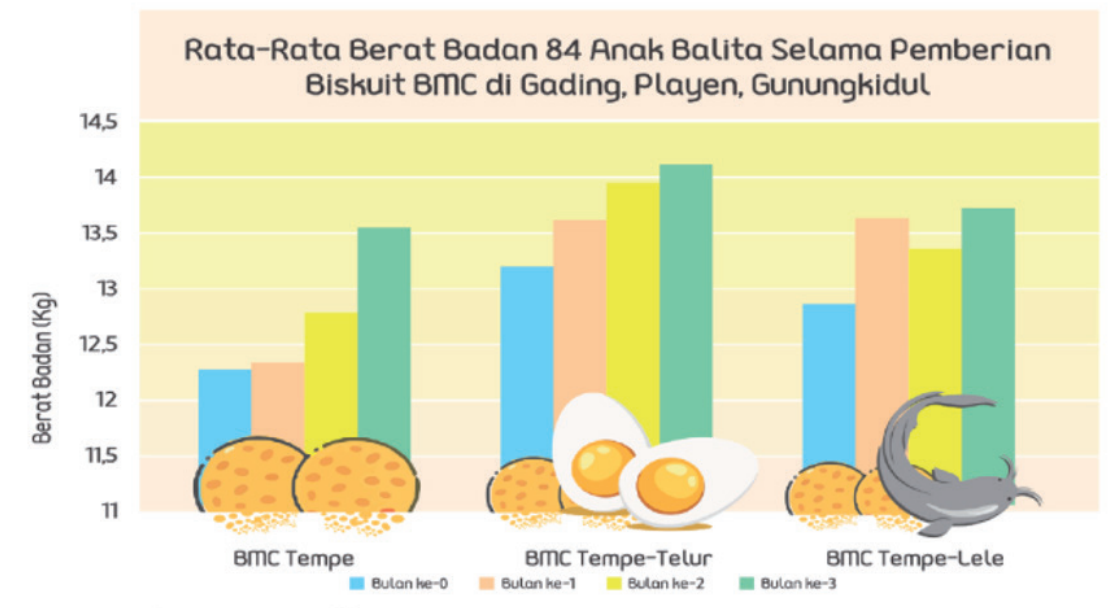

Gambar 10. Infografik "Pemberian Bahan Makanan Campuran (BMC) terhadap Berat Badan Balita" dalam buku "Produk Pangan Berbasis Tempe dan Aplikasinya" (Ariani \& Angwar, 2018)

Gambar 10 adalah infografik yang memvisualisasikan data pemberian Bahan Makanan Campuran (BMC) terhadap berat badan balita". Berdasarkan teori Lankow, kekuatan yang ditonjolkan ada pada daya tarik representasi visual dari masing-masing BMC, yakni tempe, tempe-telur, dan tempe-lele. Ketiga ilustrasi tersebut menjadi hook untuk memikat atensi pembaca untuk fokus meski tidak sekuat ilustrasi balita pada Gambar 9. Hal tersebut karena kurangnya kontras dengan warna grafik balok dan background yang seharusnya memiliki opacity lebih rendah.

Pemilihan warna yang beragam sehingga menurunkan aspek kontras cukup beralasan karena data yang ditampilkan lebih kompleks dari infografik pada Gambar 9. Penggunaan warna yang beragam adalah untuk membedakan antara bulan ke-0, bulan ke-1, bulan ke-2, dan bulan ke-3 sehingga data akan lebih mudah dipahami oleh pembaca. Penyematan teks di bagian atas menggunakan font yang bertipe rounded agar senada dengan grafik dan representasi visual yang digunakan dalam infografik.

Infografik pada Gambar 9 dan Gambar 10 masih tetap terlihat menonjol apabila diletakkan pada jenis layout naskah yang tidak terlalu banyak menggunakan ornamen dekoratif seperti terlihat pada Gambar 8. Gambar 9 dan Gambar 10 dapat dikategorikan sebagai infografik yang mampu memberikan stimulus daya tarik perhatian dan merangsang pemahaman, keduanya pada akhirnya memudahkan untuk dapat mengingat informasi secara lebih baik. 


\subsection{Hasil Perbandingan}

Berdasarkan analisis terhadap dua buku bidang pangan fungsional tersebut, dapat diketahui adanya perbedaan yang mencolok antara visualisasi data buku "Peluang Adopsi Inovasi Berbasis Data Paten di Bidang Pangan Fungsional" dengan infografik buku "Produk Pangan Berbasis Tempe dan Aplikasinya". Terutama dalam bentuk visualisasi dan kompleksitas informasi yang disampaikan.

Visualisasi data berupa diagram dan grafik merupakan bagian dari infografik. Kompleksitas dari infografik seperti yang ditunjukkan pada Buku "Produk Pangan Berbasis Tempe dan Aplikasinya" mampu menggabungkan beberapa elemen visualisasi data dalam sebuah rangkaian yang lebih informatif. Infografik buku "Produk Pangan Berbasis Tempe dan Aplikasinya" memberikan dampak terutama dalam hal menarik atensi, mempercepat pemahaman dan memberikan retensi ingatan yang lebih lama di benak pembaca dibandingkan visualisasi data buku "Peluang Adopsi Inovasi Berbasis Data Paten di Bidang Pangan Fungsional". Ketiga aspek tersebut berpeluang mendorong transfer pengetahuan dan berdampak pada mengedukasi pembaca secara lebih efektif.

Satu hal yang menarik dari hasil membandingkan visualisasi data dari buku "Peluang Adopsi lnovasi Berbasis Data Paten di Bidang Pangan Fungsional" dan infografik dalam buku "Produk Pangan Berbasis Tempe dan Aplikasinya" adalah dalam kekuatannya menarik perhatian pembaca. Terutama mengingat bahwa rentang waktu perhatian manusia yang semakin menurun.

Pentingnya senantiasa memikat perhatian pembaca merupakan salah satu peluang yang dimiliki oleh infografik. Sifat infografik yang singkat dan tajam seperti yang ditunjukkan pada buku "Produk Pangan Berbasis Tempe dan Aplikasinya" bekerja dengan baik terutama ketika rentang perhatian manusia semakin menurun. Dibandingkan harus membaca teks untuk mengakses informasi lebih banyak, informasi singkat seperti dampak biskuit BMC terhadap kenaikan berat badan balita yang ditampilkan dalam infografik pada buku "Produk Pangan Berbasis Tempe dan Aplikasinya" dapat segera dipahami oleh pembaca sebelum rentang perhatian menurun.

\section{KESIMPULAN}

Kebanyakan pembaca buku dengan data yang banyak seperti buku ilmiah, lebih sering membaca teks yang diyakini sebagai ikhtisar dari data yang ditampilkan dibandingkan mencerna data tersebut sebagai bagian tak terpisahkan dari teks dan dapat memberikan informasi yang lebih banyak. Namun demikian, dengan diolahnya data menjadi infografik, dapat menjadi bagian yang saling melengkapi bahkan bisa menggantikan teks naskah dalam buku ilmiah.

Berdasarkan analisis, infografik buku "Buku Produk Pangan Berbasis Tempe dan Aplikasinya" cukup memberikan representasi visual yang baik dalam menarik atensi dan memberikan pemahaman data terkait dengan bidang pangan fungsional. Atensi yang seimbang antara infografik dan naskah membuat keduanya dapat menempatkan informasi yang lebih kompleks di pikiran pembaca. Tidak hanya di bidang pangan fungsional, keunggulan tersebut memberikan peluang bagi infografik untuk digunakan dalam bidang-bidang lain yang membutuhkan percepatan transfer informasi dan edukasi kepada masyarakat.

Kaitan infografik dengan rentang perhatian manusia yang semakin menurun juga dapat menjadi pertimbangan yang cukup kuat bahwa nantinya infografik akan menjadi sebuah standar dalam penyajian data informasi. Perlu dipahami agar dalam membuat infografik tidak terjebak hanya pada aspek visual yang menarik sehingga mengesampingkan aspek penyampaian pemahaman. Desainer sebaiknya tidak hanya mengedepankan idealisme melainkan berbasis pada target audiens yang akan membaca infografik tersebut. Pandangan yang salah akan infografik adalah hanya menghindari kejenuhan pada tampilan angka-angka dan detail sehingga cukup menghias grafiknya supaya terlihat lebih indah. 


\section{DAFTAR PUSTAKA}

Ariani, D., \& Angwar, M. 2018. Produk Pangan Berbasis Tempe dan Aplikasinya. Jakarta: LIPI Press.

Beegel, J. 2014. Infographics for Dummies. New Jersey: John Wiley \& Sons, Inc.

BPOM, I. 2005. Peraturan Kepala BPOM RI Nomor HK 00.05.52.0685 tentang Ketentuan Pokok Pengawasan Pangan Fungsional. Jakarta.

BPOM, I. 2016. Peraturan Kepala BPOM Republik Indonesia Nomor 13 Tahun 2016 tentang Pengawasan Klaim pada Label dan Iklan Pangan Olahan. Jakarta.

Fiorentino, L. 2004. Family Front and Centre: A Support Resource Promoting Healthy Child Development. Montreal: Jewish Family Services of the Baron de Hirsch Institute.

Hariyadi, P. 2006. Pangan Fungsional Indonesia. Foodreview Indonesia, 1(5): 8-10.

Hariyadi, P. 2015. Industri Pangan Fungsional Indonesia: Peluang untuk Membangun Kesehatan Bangsa. Food Review Indonesia, 10(5): 14-17.

Helmi, R.L. 2015. Tantangan Industri Pangan Fungsional. In Peluang Adopsi Inovasi Berbasis Data Paten di Bidang Pangan Fungsional. Jakarta.

Helmi, R.L. 2018. Penerapan Skema Inkubasi Publikasi untuk Meningkatkan Produktivitas Buku Ilmiah di Bidang Pangan Fungsional. Jakarta.

Howlett, J. 2008. Functional Foods From Science Heatlh and Claims. Brussels: ILSI Europe. http:// europe.ilsi.org.

Ida, R. 2014. Metode Penelitian Studi Media dan Kajian Budaya. Jakarta: Prenada Media Group.

Jatraningrum, D.A., \& Astuti, T.N. 2015. Peluang dan Tantangan Inovasi Hasil Riset Bidang Pangan Fungsional di Indonesia: Suatu Penutup. In Peluang Adopsi Inovasi Berbasis Data Paten di Bidang Pangan Fungsional. Jakarta: LIPI Press.

Jatraningrum, D.A., Helmi, R.L., Sachmid, D.S., \& Astuti, T.N. 2015. Peluang Adopsi Inovasi Berbasis Data Paten di Bidang Pangan Fugsional. Editor: Diah A. Jatraningrum. Jakarta: LIPI Press.

Jatraningrum, D.A., \& Sachmid, D.S. 2015. Indeks Kompetitif Berbasis Data Paten di Bidang Pangan Fungsional. In Peluang Adopsi Inovasi Berbasis Data Paten di Bidang Pangan Fungsional. Jakarta: LIPI Press.

Krum, R. 2013. Cool Infographics. New Jersey: John Wiley \& Sons, Inc.

Lankow, J., Ritchie, J., \& Crooks, R. 2012. Infographic The Power of Visual Storytelling. New Jersey: John Wiley \& Sons, Inc.

Mahelingga, D.E.I.R. 2020. Penerbitan Buku Ilmiah Daring Berbasis Open Monograph Press (OMP). Berkala Ilmu Perpustakaan, 16(2): 155-69. https://doi.org/10.22146/bip.v16i1.265.

Microsoft, M. 2015. Attention Spans. Consumer Insights. https://doi.org/10.1093/alh/ajy035.

Pudjiastuti, T.N. 2017. 50 Tahun Kiprah LIPI Untuk Bangsa. Jakarta: LIPI Press.

SendPoints. 2015. Information Made Beautiful: Infographic Design. SendPoints. 